\title{
Importancia de las imágenes y el diagnóstico etiológico en el paciente inmunocomprometido con afección del SNC
}

\author{
Marcela Ferrés G., Teresa Bidart H. y Marcela Zubieta A.
}

\section{Importance of images and etiological diagnosis of central nervous system envolvement in immunocompromised patient}

We report a 16 years old boy with diagnosis of Acute Myeloid Leukemia with severe immune suppression secondary to his primary disease and to leukemia's treatment. Early during the course of his chemotherapy he developed symptoms and signs compatible with invasive fungal disease (IFD). Lungs were primarily compromised followed by CNS involvement with manifestations of intracranial hypertension. Laboratory exams were remarkable for prolonged neutropenia and indirect evidence of Aspergillus sp infection, with successive detection of positive and increasing levels of galactoman antigen in serum. With this case we want emphasize the great importance of invasive fungal disease in immune suppressed patients and particularly the CNS compromise. This represents a medical emergency which deserves to start a complete and comprehensive microbiology diagnosis and concomitantly start an empiric antifungal treatment. The importance of neuroimaging for a correct identification of the number, location and size of CNS lesions must be highlighted. The election of MRI, if available, should be preferred due to a better performance than CT scan. Brain biopsy should be discussed when all the non invasive attempts for etiology identification have failed. The invasive fungal CNS compromise has medical treatment and the surgical drainage has to be considered for lesions greater than $2 \mathrm{~cm}$ or for those making a mass effect or have failed with medical treatment.

Key words: Immunocompromised patients, invasive fungal disease, central nervous system.

Palabras clave: Pacientes inmunocomprometidos, enfermedad fúngica invasora, sistema nervioso central.

\section{Caso clínico}

$\mathrm{V}$ arón de 16 años, portador de leucemia mieloide aguda cuyo tratamiento se inició luego de cuatro semanas del diagnóstico y que al cabo de siete días de haber recibido un ciclo de quimioterapia con citarabina, daunorubicina y etopósido presentó neutropenia y fiebre con síntomas respiratorios.

La radiografía de tórax demostró un compromiso de tipo parenquimatoso nodular y en la tomografía computarizada (TAC) se apreció un nódulo pulmonar con halo periférico.

El resultado del antígeno galactomanano de Aspergillus sp por enzimo-inmuno análisis en sangre fue de 2,6 considerándose positivo un valor índice de 0,5 o más.

Con estos argumentos se planteó una infección por Aspergillus sp y se inició tratamiento con voriconazol.

Pregunta: Con los antecedentes clínicos y de laboratorio disponibles, ¿Es esta una aspergilosis invasora: posible, probable o probada?

Respuesta: En un paciente con diagnóstico de leucemia mieloide aguda que inicia un tratamiento con tres fármacos fuertemente inmunosupresores en un avanzado estado de su enfermedad, con fiebre y neutropenia grave, quien presenta precozmente a la semana de tratamiento, imágenes sugerentes de compromiso parenquimatoso pulmonar por Aspergillus sp, y un antígeno de galactomanano positivo, evidencia indirecta de la presencia de Aspergillus sp en sangre, corresponde clasificar esta situación como una aspergilosis invasora probable.

El diagnóstico de una enfermedad fúngica invasora probada se certifica cuando hay una prueba microbiológica definitiva desde un sitio estéril como una biopsia pulmonar donde se observen hifas en el estudio histopatológico con destrucción del tejido vecino o se obtenga un cultivo positivo para Aspergillus sp.

Continuación del caso: Al cuarto día de terapia con voriconazol, el paciente presentó afasia, somnolencia, hipertensión arterial y bradicardia. La resonancia magnética (RM) de cerebro mostró edema cerebral, lesiones intra axiales y supra tentoriales de la sustancia blanca y la corteza, localizadas en el lóbulo frontal derecho y temporal izquierdo, junto a pequeñas zonas de carácter expansivo en la región temporal y occipital con focos de hemorragia, compatibles, en el contexto clínico de este paciente, con aspergilosis cerebral (Figura $2 \mathrm{~A}$ y B).

\author{
Hospital Clínico Pontificia \\ Universidad Católica de Chile \\ (MFG). \\ Clínica Santa María. Santiago, \\ Chile (TBH). \\ Hospital Exequiel González \\ Cortés. Santiago, Chile (MZA). \\ Comité de infecciones en pacientes \\ inmunocomprometidos \\ Sociedad Chilena de Infectología \\ (MFG, TBH, MZA)
}

Recibido: 9 de septiembre de 2010 Aceptado: 2 de noviembre de 2010

Correspondencia a:

Marcela Ferrés G.

mferres@med.puc.cl 
Figura 1. Tinción de PAS que muestra hifas septadas obtenidas desde drenaje quirúrgico de lesiones cerebrales.

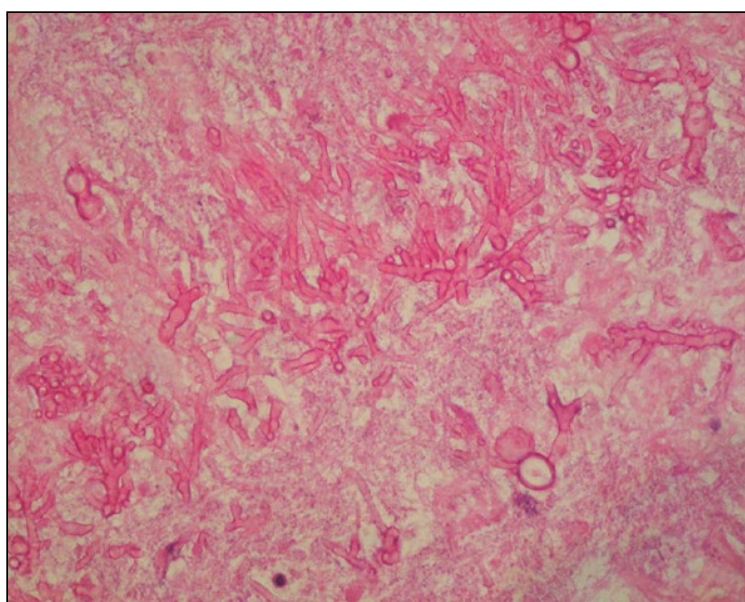

La biopsia para confirmar diagnóstico fue diferida por inestabilidad del paciente y una trombocitopenia grave. Se decidió, entonces, agregar anfotericina liposomal al tratamiento.

Posteriormente, apareció una placa eritematosa en la mejilla y dolor agudo en la cara interna del muslo. El estudio histopatológico de la lesión cutánea mostró hifas gruesas de morfología sugerente de mucormicosis y la tinción inmuno-histoquímica para Aspergillus sp fue negativa. La ecografía del muslo mostró un nódulo con necrosis central. Por la neutropenia mantenida recibió una transfusión de granulocitos logrando un alza en el recuento de leucocitos hasta $12.000 / \mathrm{mm}^{3}$ con mejoría transitoria de su estado general; no obstante, a la semana post transfusión una infección viral intercurrente (influenza A H1N1) hizo descender nuevamente el recuento de leucocitos y plaquetas.

Durante su evolución presentó compromiso de conciencia progresivo y las imágenes de RM cerebral evidenciaron desviación de la línea media por crecimiento de la lesión temporal izquierda. El valor índice del antígeno galactomanano en sangre aumentó a 5,6.

En un período de estabilidad se le realizó una cirugía cerebral descompresiva y toma de muestra para cultivo y biopsia. Las tinciones para bacterias y hongos fueron negativas y en el cultivo creció una colonia de Paecilomyces sp que fue interpretado como contaminación.

La histopatología mostró hifas septadas, con inmunohistoquímica positiva para Aspergillus sp (Figura 1).

Controlado este episodio, el paciente fue dado de alta continuando con terapia antifúngica ambulatoria. Reingresó por crisis convulsiva generalizada, con signos de hipertensión endocraneal. Las imágenes cerebrales evidenciaron esta vez el crecimiento de las lesiones frontal y occipital por lo que se realizó nuevo drenaje y resección de la cápsula del absceso.
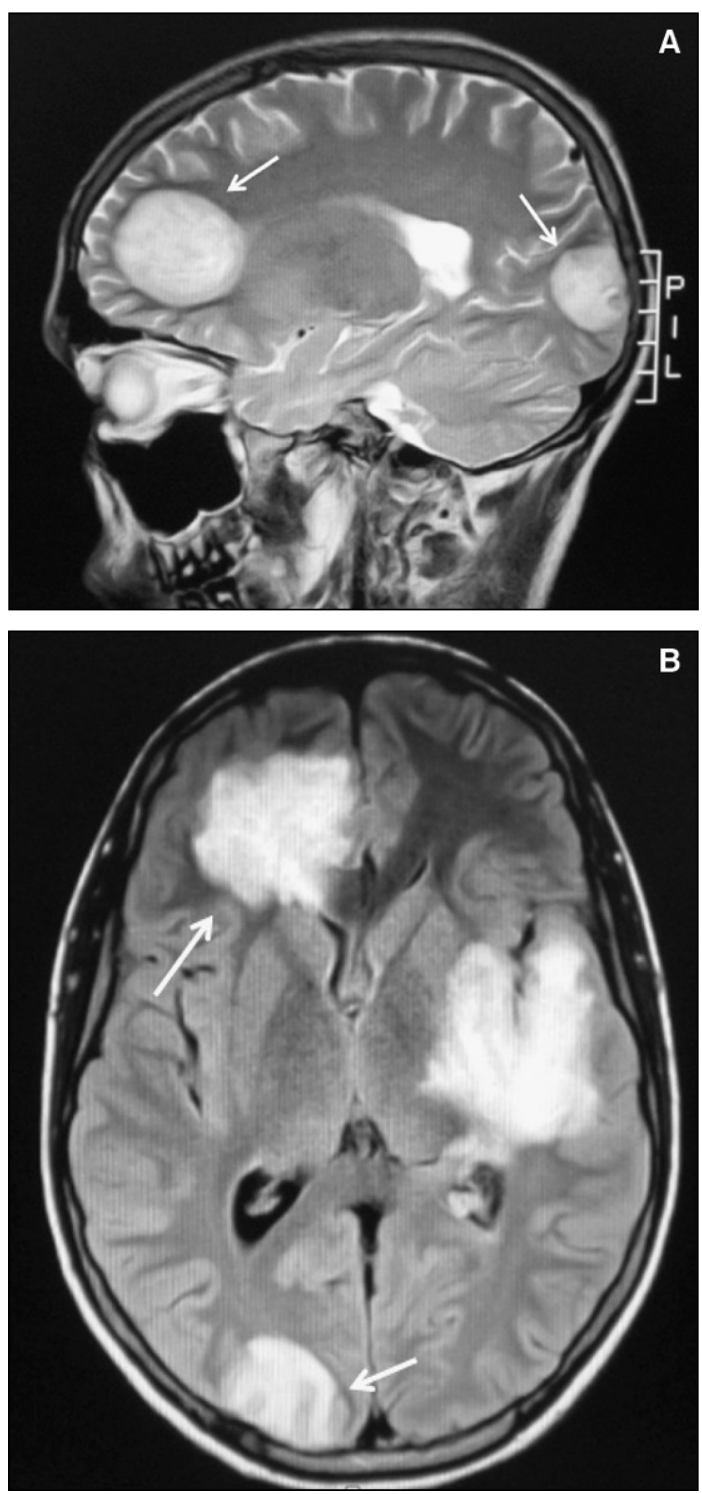

Figura 2. Caso actual. RM cerebral en cortes sagital T2 (A) y axial T1 (B) muestran múltiples lesiones intraparenquimatosas bilaterales, hiperintensas en ambas secuencias, con un componente hemorrágico (flechas).

Las tinciones de la biopsia mostraron abundantes hifas septadas; el cultivo fue negativo. La antigenemia para galactomanano había descendido a 0,8 .

El paciente continuó con tratamiento antifúngico prolongado hasta su recuperación.

\section{Diagnósticos de egreso:}

- Leucemia mieloide aguda.

- Neutropenia prolongada

- Aspergilosis invasora probada, con compromiso pulmonar y cerebral. 


\section{Infecciones fúngicas del sistema nervioso central en pacientes inmunocomprometidos}

El sistema nervioso central (SNC) de los pacientes inmunocomprometidos es particularmente susceptible a infecciones por bacterias, virus, parásitos y hongos. La supresión del sistema inmune del hospedero modifica la presentación clínica y dificulta, tanto su diagnóstico como el tratamiento.

Las complicaciones neurológicas ocurren en $\sim 30$ a $60 \%$ de los pacientes con trasplantes de órganos sólidos, y en $\sim 2$ al $70 \%$ de los sometidos a trasplante de precursores hematopoyéticos. Las causas infecciosas representan alrededor de 5 a 10\% de las complicaciones del SNC en estos pacientes ${ }^{1-3}$.

El uso de nuevos antifúngicos y la profilaxis de infecciones virales, bacterianas y parasitarias ha reducido la proporción de infecciones como causa de complicaciones del SNC pasando a ser la toxicidad por fármacos la causa más frecuente en la actualidad ${ }^{2}$.

Las etiologías más habituales de infección fúngica del SNC en este escenario son Aspergillus fumigatus y Criptococcus neoformans, observándose en la actualidad un incremento de las infecciones parasitarias y de la gravedad de éstas ${ }^{4}$.

La aspergilosis del SNC es una complicación devastadora y la más letal de las infecciones causadas por el género Aspergillus. Generalmente alcanza el cerebro por diseminación hematógena desde un foco pulmonar o por extensión directa desde los senos paranasales 5 .

La criptococosis en receptores de trasplantes se manifiesta por enfermedad diseminada o meningo-encefalitis. Estos pacientes tienen riesgo de síndrome de reconstitución inmune y aumenta el riesgo de rechazo del injerto ${ }^{6}$. En 33\% de los enfermos con criptococcosis diseminada se han descrito lesiones en el parénquima cerebral al estudio con $\mathrm{RM}^{7}$.

En suma, las infecciones fúngicas del SNC en pacientes inmunocomprometidos son una emergencia médica y se deben enfrentar en forma pro-activa y rápida instaurando tratamiento empírico hasta completar el estudio. La eva- luación debe ser guiada por el grado de inmunosupresión, el tipo de trasplante, el tiempo desde el trasplante, los síntomas sistémicos concomitantes, los cultivos, los estudios de biología molecular y, especialmente, los hallazgos de neuro-imágenes. Es necesario priorizar la RM debido a su mayor rendimiento y, de no ser posible aclarar la etiología con métodos no invasores, se debe realizar biopsia cerebral a la brevedad. El tratamiento es médico-quirúrgico y tienen indicación de drenaje todas aquellas lesiones de un tamaño mayor a 2 centímetros, las que tienen efecto de masa o son refractarias al tratamiento médico.

\section{Resumen}

Comunicamos el caso de un adolescente de 16 años, con una leucemia mieloide aguda y una grave inmunosupresión secundaria a su enfermedad y el tratamiento. Precozmente post-quimioterapia desarrolló síntomas y signos compatibles con una enfermedad fúngica invasora (EFI). Inicialmente se afectaron sus pulmones y a continuación el SNC con hipertensión intracraneal. Los exámenes de laboratorio indicaron una neutropenia prolongada y evidencias indirectas de una infección por Aspergillus sp mediante la medición sucesiva de galactomanano positivo en sangre y un segundo valor en ascenso. Con este caso enfatizamos la gran importancia que tienen las EFI en pacientes inmunocomprometidos, particularmente sobre el SNC. Ellas representan una emergencia médica que requiere de una confirmación microbiológica y el inicio temprano de terapia anti-fúngica empírica.

Debe destacarse la importancia que tienen las neuroimágenes en la correcta identificación del número de lesiones, su localización y tamaño. La RM, si está disponible, debiera ser la elección, para una mejor definición, por sobre el uso de la TAC. Igualmente, debiera discutirse la indicación de biopsia cerebral cuando todos los métodos no invasores han fracasado en precisar la etiología. La EFI del SNC es de tratamiento médico, debiéndose considerar el drenaje quirúrgico de las lesiones con más de $2 \mathrm{~cm}$ de diámetro o aquellas que ejercen efecto de masa o, finalmente, cuando ha fracasado el manejo con anti-fúngicos.

\section{Referencias}

1.- Zunt J R. Central nervous system infection during immunosupression. Neurol Clin 2002; 20 (1): 1-22.

2.- Battle M, Oriol A, Ribera J M, Lozano M, Ferrá C, Sancho J M, et al. Complicaciones neurológicas después de un trasplante de progenitores hematopoyéticos. Estudio de 14 pacientes. Medicina Clínica 2005; 125 (18): 697-9.

3.- Walker M, Kublin J G, Zunt J R. Parasitic central nervous system infections in immunocompromised host: Malaria, microsporidiosis, leishmaniasis and african trypanosomiasis. Clin Infect Dis 2006; 42 (1): 115-25.

4.- Rovira Tarrats M, Carreras Pons E, Sierra Gil J, et al. Infecciones en receptores de trasplante de progenitores hematopoyéticos. Medicine 1998; 7 (82): 3837-43.

5.- WalshT J, Anaisse E J, Denning D W, Herbrecht R, Kontoyiannis D P, Marr K A, et al. Treatment of aspergillosis: Clinical Practice Guidelines of the Infectious Diseases Society of America. Clin Infect Dis 2008; 46
(3): $327-60$.

6.- Singh N, Dromer F, Perfect J R, Lortholary O. Cryptococcosis in solid organ transplant recipients. Current state of the science. Clin Infect Dis 2008; 47 (10): 1321-7. Review.

7.- Perfect J R, Dismukes W E, Dromer F, Goldman D L, Graybill J R, Hamill R J, et al. Clinical Practice Guidelines for the management of cryptoccal diseases 2010 Update by the Infectious Diseases Society of America. Clin Infect Dis 2010; 50 (3): 291-322. 